\title{
Structures of Human Monoamine Oxidase B Complexes with Selective Non-covalent Inhibitors: Safinamide and Coumarin Analogs
}

Claudia Binda, Jin Wang, Leonardo Pisani, Carla Caccia, Angelo Carotti, Patricia Salvati, Dale E. Edmondson, Andrea Mattevi

\section{Supporting information}

\section{Table of Contents}

Elemental analysis of compounds $\mathbf{2}$ and $\mathbf{3}$

Enzymatic and crystallographic methods

References

Figure S1 showing the electron density of human MAO B-bound safinamide

Figure S2 showing the electron density of human MAO B-bound compound 2 


\section{Elemental analysis of compounds 2 and 3}

\begin{tabular}{|c|c|c|c|c|c|c|}
\hline & \multicolumn{3}{|c|}{ Calculated, \% } & \multicolumn{3}{c|}{ Observed, \% } \\
\hline Entry & $\mathrm{C}$ & $\mathrm{H}$ & $\mathrm{N}$ & $\mathrm{C}$ & $\mathrm{H}$ & $\mathrm{N}$ \\
\hline $\mathbf{2}$ & 53.58 & 4.73 & 3.29 & 53.90 & 4.66 & 3.31 \\
\hline $\mathbf{3}$ & 64.88 & 3.52 & & 65.07 & 3.39 & \\
\hline
\end{tabular}

\section{Enzymatic and crystallographic methods}

Human recombinant MAO A and MAO B were expressed in Pichia pastoris and purified as described. ${ }^{1,2}$ Purified protein samples were stored in $50 \mathrm{mM}$ potassium phosphate buffer $\mathrm{pH}$ 7.5, $0.8 \%(\mathrm{w} / \mathrm{v}) \beta$-octylglucoside. Enzymatic activity and $\mathrm{K}_{\mathrm{i}}$ evaluation (Table 1 ) were determined as described. ${ }^{3}$ Briefly, MAO A and MAO B activities were monitored spectrophotometrically using kynuramine (316 $\mathrm{nm})$ and benzylamine $(250 \mathrm{~nm})$ as substrates, respectively, in $50 \mathrm{mM}$ potassium phosphate buffer $\mathrm{pH}$ 7.5, $0.5 \%$ (w/v) reduced Triton $\mathrm{X}-100$ at $25^{\circ} \mathrm{C}$.

Human MAO B in 50 mM potassium phosphate pH 7.5, 8.5 mM Zwittergent 3-12 was cocrystallized with the investigated inhibitors by mixing equal volumes of protein sample and reservoir solution (12\% PEG4000, 100 mM ADA buffer pH 6.5, $70 \mathrm{mM} \mathrm{Li}_{2} \mathrm{SO}_{4}$ ). X-ray diffraction data were collected at the Swiss Light Source in Villigen and at the beam-line ID14-EH2 of European Synchrotron Radiation Facility in Grenoble. For data collection, crystals were transferred into a mother liquor solution containing $18 \%(\mathrm{v} / \mathrm{v})$ glycerol and flash-cooled in a stream of gaseous nitrogen at 100 K. Data processing and scaling (Table 2) were carried out using MOSFLM ${ }^{4}$ and programs of the CCP4 package. ${ }^{5}$ The coordinates of the MAO B-isatin complex ${ }^{6}$ were used as initial model after removal of all water and inhibitor atoms. Inhibitor molecules were modelled using unbiased $2 \mathrm{~F}_{\mathrm{O}}-\mathrm{F}_{\mathrm{c}}$ and $\mathrm{F}_{\mathrm{o}}-\mathrm{F}_{\mathrm{c}}$ maps (Figure $\mathrm{S} 1$ ) by means of the program O. ${ }^{7}$ Crystallographic refinements were performed with the programs REFMAC5 ${ }^{8}$ and WARP. ${ }^{9}$ Tight noncrystallographic symmetry restraints were applied throughout the refinement calculations. Refinement statistics are listed in Table 2. Inhibitor binding does not induce any significant 
conformational change. The root-mean-square deviation values calculated from superposing the investigated structures onto the MAO B-isatin complex fall in the range 0.25-0.40 $\AA$ (997 equivalent $\mathrm{C} \alpha$ atoms of the dimer). Cavities were identified with the program Voidoo. ${ }^{10}$ Pictures were produced by using Pymol (www.pymol.org), Bobscript, ${ }^{11}$ Molscript, $^{12}$ and Raster3d. ${ }^{13}$

\section{References}

1. Li, M.; Hubálek, F.; Newton-Vinson, P.; Edmondson, D. E. High-Level Expression of Human Liver Monoamine Oxidase A in Pichia pastoris: Comparison with the Enzyme Expressed in Saccharomyces cerevisiae. Protein Expr. Purif. 2002, 24, 152-162.

2. Newton-Vinson, P.; Hubálek F.; Edmondson, D. E. High-level Expression of Human Liver Monoamine Oxidase B in Pichia pastoris. Protein Expr. Purif. 2000, 20, 334-345.

3. Hubalek, F.; Binda, C.; Li, M.; Herzig, Y.; Sterling, J.; Youdim, M.B.; Mattevi, A.; Edmondson, D.E. Inactivation of Purified Human Recombinant Monoamine Oxidases A and B by Rasagiline and Its Analogues. J. Med. Chem. 2004, 47, 1760-1766.

4. Leslie, A.G.W. Integration of Macromolecular Diffraction Data. Acta Crystallogr. 1999, D55, 1696-1702.

5. Collaborative Computational Project, Number 4. The CCP4 Suite: Programs for protein Crystallography. Acta Crystallogr. 1994, D50, 760-767. 
6. Binda, C.; Li, M.; Hubalek, F.; Restelli, N.; Edmondson, D. E.; Mattevi, A. Insights into the Mode of Inhibition of Human Mitochondrial Monoamine Oxidase B from High-resolution Crystal Structures. Proc. Natl. Acad. Sci. USA 2003, 100, 9750-9755.

7. Jones, T. A.; Zou, J. Y.; Cowan, S. W; Kjeldgaard, M. Improved Methods for Building Protein Models in Electron Density Maps and the Location of Errors in These Models. Acta Crystallogr. 1991, A47, 110-119.

8. Murshudov, G. N.; Vagin, A. A.; Dodson, E. J. Refinement of Macromolecular Structures by the Maximum-Likelihood Method. Acta Crystallogr. 1997, D53, 240-255.

9. Morris, R. J.; Perrakis, A.; Lamzin, V. S. ARP/wARP's Model-building Algorithms. I. The Main Chain. Acta Crystallogr. 2002, D58, 968-75.

10. Kleywegt, G. J.; Jones, T. A. Detection, Delineation, Measurement and Display of Cavities in Macromolecular Structures. Acta Crystallogr. 1994, D50, 178-185.

11. Esnouf, R. M. Further Additions to MolScript Version 1.4, Including Reading and Contouring of Electron-density Maps. Acta Crystallogr. 1999, D55, 938-940.

12. Kraulis, P. J. J. MOLSCRIPT: a Program to Produce both Detailed and Schematic Plots of Protein Structures. Appl. Crystallogr. 1991, 24, 946-950.

13. Merritt, E. A.; Bacon, D. J. Raster3D: Photorealistic Molecular Graphics. Methods in Enzymology 1997, 277, 505-524. 


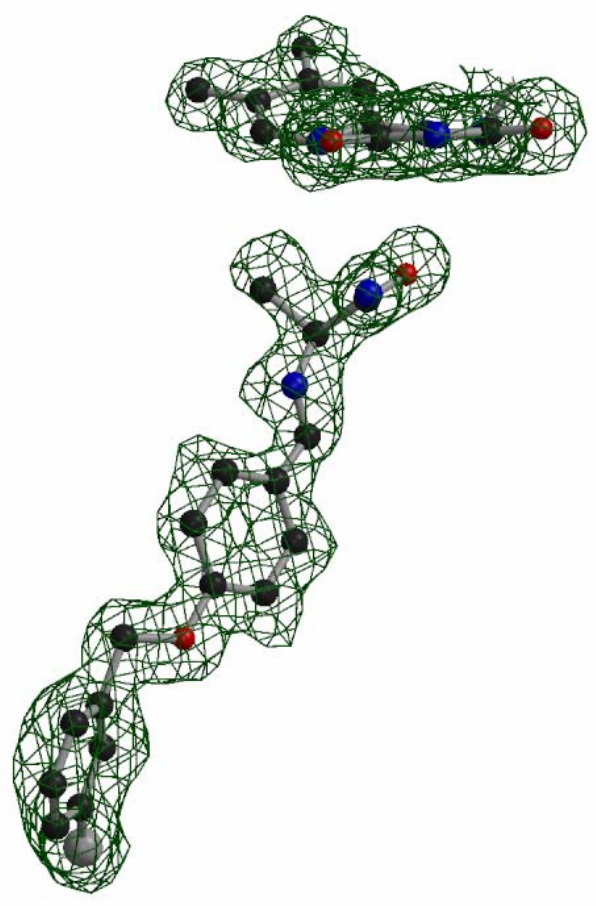

Figure S1. Unbiased $2 \mathrm{~F}_{\mathrm{o}}-\mathrm{F}_{\mathrm{c}}$ electron density map (contoured at $1 \sigma$ level) of safinamide clearly showing that the inhibitor is non-covalently bound in front of the flavin cofactor. The orientation is the same as in Figure 2a. The colour code for atoms is as follows: $\mathrm{C}$ in black, $\mathrm{N}$ in blue, $\mathrm{O}$ in red, $\mathrm{F}$ in gray. 


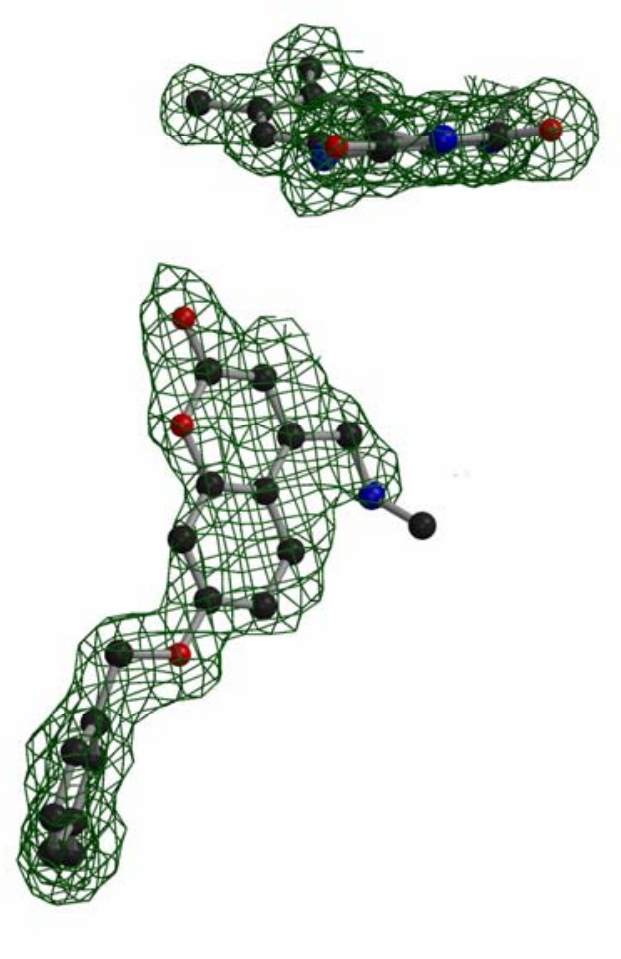

Figure S2. Unbiased $2 \mathrm{~F}_{\mathrm{o}}-\mathrm{F}_{\mathrm{c}}$ electron density map (contoured at $1 \sigma$ level) of compound 2 (see Figure 3b). The orientation and colour code are the same as in Figure S1. 